\title{
Chromatin and epigenetic regulation of the telomerase reverse transcriptase gene
}

\author{
Jiyue Zhu (ه), Yuanjun Zhao, Shuwen Wang
}

Department of Cellular and Molecular Physiology, Pennsylvania State University College of Medicine, Hershey, PA 17033, USA

$\triangle$ Correspondence: joz1@psu.edu

Received November 26, 2009; accepted December 3, 2009

\begin{abstract}
Telomerase expression and telomere maintenance are critical for long-term cell proliferation and survival, and they play important roles in development, aging, and cancer. Cumulating evidence has indicated that regulation of the rate-limiting subunit of human telomerase reverse transcriptase gene ( $h T E R T)$ is a complex process in normal cells and many cancer cells. In addition to a number of transcriptional activators and repressors, the chromatin environment and epigenetic status of the endogenous $h T E R T$ locus are also pivotal for its regulation in normal human somatic cells and in tumorigenesis.
\end{abstract}

KEYWORDS telomerase, transcriptional regulation, chromatin, epigenetic regulation, cancer

\section{INTRODUCTION}

Telomeres serve as essential protective caps of linear chromosomal ends in all eukaryotic cells and their maintenance is indispensable for indefinite proliferative potential. The telomeric TTAGGG repeats are replenished by telomerase (Morin, 1989), a ribonucleoprotein complex that consists of a catalytic reverse transcriptase protein subunit (TERT) (Harrington et al., 1997; Lingner et al., 1997; Meyerson et al., 1997), an RNA template (TERC) (Shippen-Lentz and Blackburn, 1990; Blasco et al., 1995; Collins, 2000), dyskerin (Cohen et al., 2007), and other accessory proteins (Venteicher et al., 2009). In most human tissues, telomerase is either absent or expressed at extremely low levels (Wright et al.,
1996; Masutomi et al., 2003). Consequently, somatic cells suffer telomere attrition upon successive divisions and undergo a crisis (defined as massive cell death) or a permanent cell cycle arrest (replicative senescence) at the end of their lifespan, namely the Hayflick limit.

Telomere maintenance by telomerase plays an important role in human aging and tumorigenesis. Although telomerase is barely detectable in most adult human cells, it is expressed in over $90 \%$ of immortal cell lines and cancers (Kim et al., 1994; Shay and Bacchetti, 1997; Hahn et al., 1999b). Telomerase knockout mice $\left(m T E R C^{-/-}\right)$display impairment in organs consisting of highly proliferative tissues and exhibit premature aging (Blasco et al., 1997; Rudolph et al., 1999). Whereas the RNA subunit, TERC, is abundant in most tissues (Blasco et al., 1996), TERT expression is the rate-limiting step in telomerase expression. The level of hTERT mRNA is tightly regulated and correlated with telomerase activity (Meyerson et al., 1997; Nakamura et al., 1997). It has been demonstrated that ectopic hTERT expression in many cell types results in telomere stabilization, immortalization, and tumorigenic conversion of pre-neoplastic human cells (Bodnar et al., 1998; Counter et al., 1998; Hahn et al., 1999a; Zhu et al., 1999). In the past decade, regulation of the hTERT gene has been a focus of many studies. It has been revealed that the hTERT promoter is regulated by many transcription factors and signaling pathways. Since these research progresses have been discussed in a number of recent review articles (Ducrest et al., 2002; Janknecht, 2004; Liu et al., 2004; Dwyer et al., 2007; Kyo et al., 2008), we will emphasize on the epigenetic and chromatin mechanisms of hTERT regulation in this review. 


\section{EXPRESSION OF THE ENDOGENOUS $h T E R T$ GENE AND ITS TRANSGENIC MODELS}

The $h T E R T$ gene undergoes repression as embryonic cells differentiate into adult somatic cells. At early embryonic stages, telomerase activity is present at a high level in many tissues (Wright et al., 1996). From the neonatal period onward, this activity can no longer be detected (Kim et al., 1994; Wright et al., 1996), except in some highly proliferative tissues, such as hematopoietic cells and cells of the basal layer of epidermis (Weng et al., 1996; Yasumoto et al., 1996). In addition, the $h T E R T$ gene is also expressed in stem cells of different types (Chiu et al., 1996).

Significant differences exist in telomerase regulation and telomere length control among different species. Although telomere shortening functions as a mitotic clock for cellular senescence in human cells, telomere-mediated replicative aging does not appear to be a critical controlling mechanism for the proliferation of mouse cells (Forsyth et al., 2005). Whereas the $h T E R T$ gene is tightly repressed in most human somatic tissues (Kim et al., 1994; Shay and Bacchetti, 1997), telomerase expression in mice is less restricted, with many tissues expressing significant levels of mTERT mRNA
(Prowse and Greider, 1995; Greenberg et al., 1998; MartinRivera et al., 1998; Horikawa et al., 2005). This difference likely contributes to the much longer telomeres in mouse cells and to some of the distinct characteristics of tumor development in mice than in humans.

The TERT locus and its neighboring loci are arranged in the same order in humans and mice (Fig. 1). The upstream CRR9 gene is ubiquitously expressed in all cell lines and tissues that have been examined (Wang et al., 2004), whereas the downstream Xtrp2 gene is expressed exclusively in kidney (Nash et al., 1998). Though exon sequences of the TERT genes are conserved between the two species, flanking sequences are highly diverged (Greenberg et al., 1999). In particular, the intergenic regions between the $C R R 9$ and TERT loci are $23 \mathrm{~kb}$ and $6 \mathrm{~kb}$ in human and mouse genomic sequences, respectively (Fig. 2). This size difference is largely attributable to the presence of abundant Aluelements and other human-specific repetitive sequences, which accounted for about half of the 23-kb sequence in intergenic region. It would be reasonable to speculate that such human-specific repetitive elements are more prone to form repressive chromatin structure in human cells than in mouse cells. Indeed, the intergenic region is highly resistant

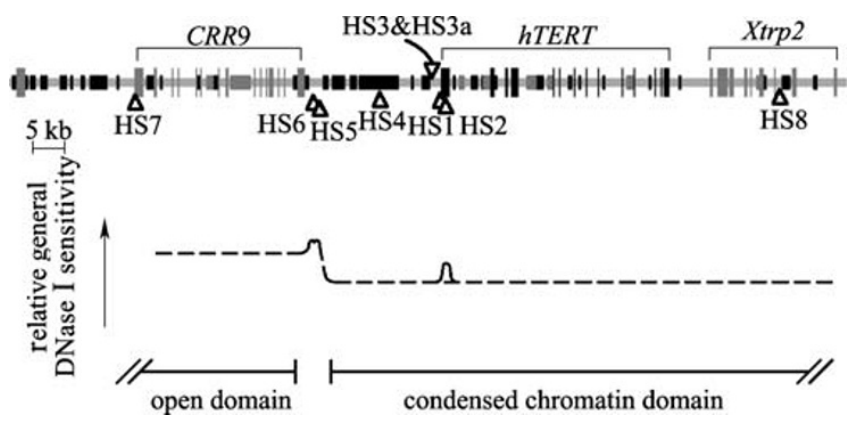

Figure 1. A schematic illustration of the genomic structures and chromatin conformations around the hTERT locus. The top part is a display of the genomic region containing the $h T E R T, C R R 9$, and Xtrp2 loci. Exons are designated as tall vertical rectangles and lines. Short black rectangles represent repetitive elements and short gray rectangles are mini-satellite sequences. The positions of DHSs are indicated by triangles. The lower part summarizes the general DNase I sensitivity of the genomic regions around the hTERT locus in human somatic cells and cell lines that have been examined (Wang and Zhu, 2004; Wang et al., 2009).

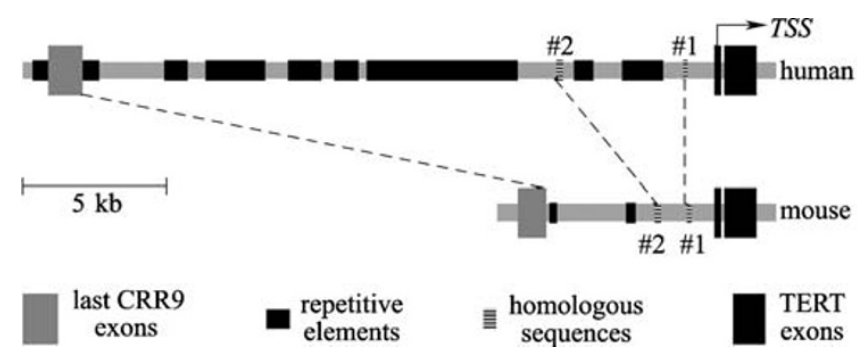

Figure 2. The comparison of $5^{\prime}$ integenic regions of the $h T E R T$ and $m T E R T$ loci. \#1 and \#2 are human and mouse homology regions. TSS, transcription start site. 
to nuclease digestion in both telomerase-positive and negative human cells (Wang and Zhu, 2004; Wang et al., 2009) (Fig. 1). Therefore, it is likely that the intergenic regions upstream of the TERT promoters are important for the differential regulation of TERT genes.

Studies on transgenic mouse lines containing human genomic sequences indicated that cis elements were important for species-specific regulation of the hTERT promoter. The expression profile of a LacZ reporter controlled by an 8-kb hTERT promoter fragment in transgenic mice was overall similar to that of the $h T E R T$ gene, albeit with variations among transgenic lines (Ritz et al., 2005). Horikawa et al. also reported a transgenic mouse strain with a BAC containing the hTERT gene, an 11-kb upstream region, and a $1.2-\mathrm{kb}$ downstream sequence. The hTERT expression profile in this transgenic mouse line was very similar to the endogenous $h T E R T$ gene, with little expression in most adult somatic tissues, except testis, ovary, and thymus (Horikawa et al., 2005). Recent data from our transgenic mouse model indicated that an hTERT reporter from an integrated BAC construct, including the entire $h T E R T$ locus and its upstream and downstream neighbors, CRR9 and Xtrp2 loci, recapitulated the regulation of the endogenous $h T E R T$ gene in human tissues (unpublished results). Taken together, these results demonstrated that (1) the BAC constructs contained sufficient cis elements for the human-specific developmental programming of the $h T E R T$ gene; and (2) mouse cells contained all the trans-acting factors involved in the developmental regulation of the $h T E R T$ gene.

\section{REGULATION OF THE hTERT PROMOTER FUNCTION}

Studies have indicated that regulation of hTERT transcription is the primary control mechanism for regulating telomerase activity during development and cellular immortalization, although post-transcriptional events, such as alternatively spliced hTERT messages and hTERT protein phosphorylation, have also been reported (Kang et al., 1999; Aisner et al., 2002). The core region of the hTERT promoter contains a number of consensus sequences for known transcription factors that are likely involved in its regulation, including Eboxes, GC-boxes, Ets and E2F consensus sites (Fig. 3) (Horikawa et al., 1999; Wick et al., 1999; Wu et al., 1999).

It was reported that overexpression of the proto-oncogene c-Myc, which bound to the E-boxes, activated hTERT expression in normal cells (Horikawa et al., 1999; Takakura et al., 1999; Wu et al., 1999). Several other transcription factors, including Sp1, ER, Ets, AP1, E2Fs, and NF-kB, have also been implicated in $\mathrm{hTERT}$ regulation via their consensus binding sites within or near the core promoter (Fig. 3) (Kyo et al., 1999; Kyo et al., 2000; Crowe et al., 2001; Akiyama et al., 2003; Goueli and Janknecht, 2004; Takakura et al., 2005; Xu et al., 2008a). Although these regulatory mechanisms of hTERT expression may be important under specific physiological conditions, none of these factors has been associated with immortalization of somatic cells. Several years ago, Hahn and colleagues reported a low-level hTERT expression in normal human fibroblasts (Masutomi et al., 2003). Although this low level of telomerase was insufficient to prevent telomere shortening, it was important for the structural integrity of telomeres in these fibroblasts. Thus, some of the aforementioned factors may be important to maintain the lowlevel hTERT transcription and telomere integrity in normal somatic cells.

Several negative regulatory factors have been reported to bind to the hTERT promoter and mediate its repression. The downstream E-box (+44 nt, relative to the transcription start site, or TSS, Fig. 3) was proposed to play an important role in both positive and negative regulation of hTERT transcription. This E-box was found to mediate the repression of hTERT promoter by Mad1 and USF1 in several cell types (Günes et al., 2000; Horikawa et al., 2002; Lin and Elledge, 2003). The GC-boxes, binding sites for Sp1/Sp3 transcription factors, were essential for hTERT promoter activity and might also be involved in repression by recruiting HDACs (Wu et al., 1999; Kyo et al., 2000; Won et al., 2002). In addition, other sites, including X-box, E2F, MT-box, WT-1 (Wilm's tumor 1), and MZF-2 sites, might also mediate the repression of hTERT transcription by different transcriptional repressors (Oh et al., 1999; Fujimoto et al., 2000; Crowe et al., 2001; Xu et al., 2001; Horikawa et al., 2002; Xu et al., 2008b).

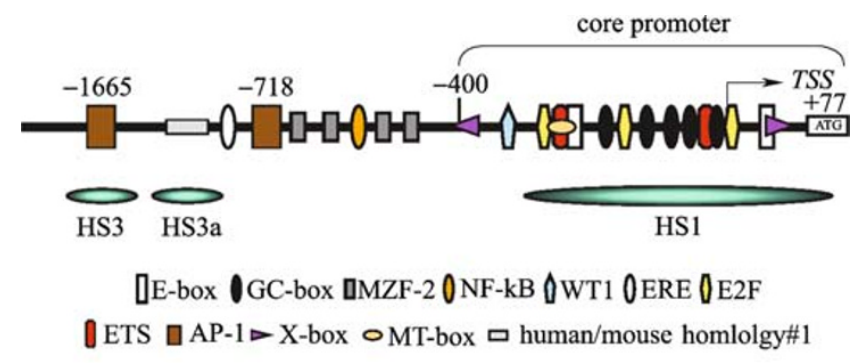

Figure 3. Summary of cis elements at the proximal region of the hTERT promoter. Blue ovals indicate the positions of DHSs in HL60 cells (Wang et al., 2009). The horizontal arrow designates the transcription start site (TSS) and the direction of transcription. Numbers are nucleotide positions relative to the TSS. ATG, hTERT translational initiation codon. 
Mechanisms of transcriptional activation and repression may coordinate the regulation of the endogenous hTERT promoter. Since c-Myc is up-regulated in many cancer cells, it is thus likely that c-Myc contributes to telomerase activation during tumorigenesis. However, c-Myc is also expressed in some proliferating normal cells in which telomerase activity is undetectable. As in cancer cells, telomerase and the hTERT gene are activated upon the formation of induced pluripotent stem cells (iPS cells) (Takahashi et al., 2007; Yu et al., 2007). Although c-Myc was reported to be one of the four reprogramming factors (Oct4, Sox2, Klf4, and c-Myc) (Takahashi and Yamanaka, 2006), it is dispensable for iPS cell induction (Wernig et al., 2008). In addition, hTERT transcription remained silenced in a subset of partially reprogrammed cells containing the highly expressed c-Myc transgene (Mathew et al., unpublished results). These results indicated that C-Myc expression was neither sufficient nor required for the activation of $h T E R T$ gene during cellular reprogramming. Therefore, mechanisms of transcriptional repression must be present in normal somatic cells to prevent the $h T E R T$ gene from being activated (Horikawa et al., 1998; Ducrest et al., 2002; Wang and Zhu, 2003).

\section{CHROMATIN AND EPIGENETIC REGULATION OF THE hTERT GENE}

Regulation of gene expression appears to be a complex process, often occurring at multiple levels. On the one hand, transcriptional activation of a promoter involves temporal actions of transcription factors, covalent modifications of core histones by chromatin modifying complexes, and ATPdependent nucleosomal remodeling at the promoter (de la Serna et al., 2006; Kaeser and Emerson, 2006). On the other hand, distinct and redundant chromatin modifications such as histone deacetylation and nucleosomal remodeling have been implicated in the transcriptional repression of several yeast genes (Zhang and Reese, 2004).

Covalent modifications of core histones, including histone acetylation, methylation, phosphorylation, and ubiquitinization, have emerged as major mechanisms for gene regulation (Jenuwein and Allis, 2001). It has been shown that, trichostatin A, a potent inhibitor of classes I and II histone deacetylases (HDACs), induced hTERT transcription in normal cells and telomerase-negative immortal cell lines (Cong and Bacchetti, 2000; Takakura et al., 2001; Hou et al., 2002; Wang and Zhu, 2003; Liu et al., 2004). In addition, hTERT transcription was also associated with hyperacetylation of core histones at the hTERT promoter in several types of cells, as revealed by chromatin immunoprecipitation (ChIP) (Xu et al., 2001; Wang et al., 2007). These results indicated that the hTERT promoter was normally repressed as a result of hypoacetylation of core histones in many human somatic cells.

In addition to histone deacetylation, histone methylation was also reported to be involved in hTERT regulation. Atkinson et al. showed that the lack of hTERT transcription in telomerase-negative immortal cells was associated with methylation at lysine 9 of histone $\mathrm{H} 3(\mathrm{H} 3 \mathrm{~K} 9)$ and lysine 20 of H4 (H4K20), whereas hTERT expression in telomerasepositive cells was accompanied by methylation at lysine 4 of histone H3 (H3K4) (Atkinson et al., 2005). Interestingly, depletion of the histone methyltransferase SMYD3 in tumor cells resulted in a reduction of histone $\mathrm{H} 3 \mathrm{~K} 4$ methylation at the hTERT promoter, accompanied by down-regulation of hTERT mRNA and telomerase activity, indicating that SMYD3 activated the hTERT promoter by methylating the H3K4 residue (Liu et al., 2007). Furthermore, inhibition of lysinespecific demethylase 1 (LSD1) by either siRNAs or a chemical inhibitor tranylcypromine led to an increase of methylation at $\mathrm{H} 3 \mathrm{~K} 4$ and an activated hTERT transcription human fibroblasts (Zhu et al., 2008). Most recently, the same group also reported that recruitment of histone demethylase RBP2 by Mad1 was involved in the transcriptional repression of the $h T E R T$ gene in leukemic HL60 cells (Ge et al., 2009). Finally, $\mathrm{Xu}$ and colleagues showed that the mitogen-activated kinase (MAPK) signaling pathway mediated histone H3 phosphorylation is required for the activation of hTERT transcription during cell proliferation in fibroblasts and $\mathrm{T}$ lymphocytes (Ge et al., 2006).

In addition to histone modifications, CpG methylation is another important epigenetic mechanism of transcriptional silencing. A CpG island is present at the 5' end of the hTERT gene, overlapping with the hTERT promoter (Wick et al., 1999). Although it has been reported that the hTERT promoter was often methylated in human cell lines and cancer cells (Devereux et al., 1999, Dessain, 2000 \#357), a clear correlation between its transcriptional activity and methylation profile has not been established. On the one hand, promoter methylation was associated with transcriptional silencing of the $h T E R T$ gene, as treatment of cells with demethylating agent 5-aza-2'-deoxycytidine resulted in an increase in hTERT transcription in an immortal fibroblast line SUSM-1 (Devereux et al., 1999). In addition, the binding of methyl-CpG-binding domain protein 2 (MBD2) to the hypermethylated hTERT promoter led to hTERT repression in Hela cells (Chatagnon et al., 2009). On the other hand, DNA hypermethylation was also implicated in the positive regulation of the hTERT promoter (Guilleret et al., 2002) because demethylation in several telomerase-positive tumor cell lines caused reduced hTERT expression and telomerase activity, which were accompanied by telomere shortening (Guilleret and Benhattar, 2003). In this case, CpG methylation likely interfered with the binding of transcriptional repressors and thereby positively regulated the hTERT promoter (Renaud et al., 2005).

The paradox for the conflicting data regarding the role of promoter methylation in hTERT regulation in cancer cells remains to be resolved. The apparent discrepancy might in 
part result from the different methods used in various studies. Using methylation-specific PCR and bisulfite sequencing methods, Zinn et al. analyzed the hTERT promoter in breast, lung, and colon cancer cells, and found that most cancer cell lines retained at least one allele with little or no methylation in a small region near TSS, in spite of dense methylation in a region $600 \mathrm{bp}$ upstream of the TSS (Zinn et al., 2007). This study suggested that demethylation at the core promoter region was required for hTERT transcription in tumor cells. Conversely, the hTERT promoter in many normal cells and tissues, in which the $h T E R T$ gene was transcriptionally silenced, was either unmethylated or hypomethylated, indicating that developmental hTERT silencing did not require extensive CpG methylation at its promoter (Devereux et al., 1999; Dessain et al., 2000; Guilleret et al., 2002; Wang et al., 2007). Although the role of $\mathrm{CpG}$ methylation in hTERT regulation may vary among different cell types, it is possible that most de novo CpG methylation at the hTERT promoter was acquired during tumor growth and/or in vitro passaging of oncogene-transformed cell lines (Dessain et al., 2000). Consistent with this notion, the $\mathrm{CpG}$ island at the hTERT promoter was more extensively methylated in SV40-transformed human fibroblasts than in their parental normal human fibroblasts, although the endogenous hTERT mRNA was detected in neither cell types (unpublished results).

In the past decade, much attention has been focused on the regulation of hTERT promoter. To this date, all cis regulatory elements that have been reported to be responsible for hTERT regulation reside in the proximal region of the hTERT promoter. In fact, the hTERT promoter in an episomal state in transient transfection experiments was highly active in both telomerase-positive and-negative cells, comparable to those of SV40 early promoter and CMV promoter (Cong et al., 1999; Ducrest et al., 2001; Wang and Zhu, 2003). In contrast, the expression of endogenous $h T E R T$ gene was tightly regulated in these cells. Even in many telomerase-positive cell lines, the endogenous $h T E R T$ gene was expressed at relatively low levels, with only a few copies of hTERT mRNA per cell (Ducrest et al., 2001; Yi et al., 2001; Renaud et al., 2003). Although posttranscriptional events, such as alternative RNA splicing events, might contribute to this drastic difference between the activity of an episomal hTERT promoter and its endogenous expression (Aisner et al., 2002), available evidences suggested that distal regulatory elements, in addition to the cis elements resided in the hTERT proximal promoter region, also played important roles in regulating the endogenous $h T E R T$ gene. Indeed, sequences within the first and second exons of the $h T E R T$ gene were found to contain binding sites for CTCF, an abundant and highly conserved nuclear factor that was primarily involved in the global organization of chromatin architecture, suggesting that chromatin environment and epigenetic mechanisms contributed to the regulation of endogenous hTERT promoter in both normal and cancer cells (Renaud et al., 2005).
Consistent with the notion that the chromatin environment is critical for the tight regulation of the $h T E R T$ gene in somatic cells, studies from our laboratory revealed that the endogenous $h T E R T$ locus was embedded in a condensed chromatin domain that was as resistant to DNase I digestion as the wellstudied $\beta$-globin loci in normal human fibroblasts and immortal cell lines, including both telomerase-positive andnegative cell lines (Wang and Zhu, 2004). This chromatin domain was at least $100 \mathrm{~kb}$ in size, extending from the 5' intergenic region of the $h T E R T$ gene to the downstream Xtrp2 locus (Fig. 1). In telomerase-positive cells, the hTERT transcription was accompanied by the appearance of a major DNase I hypersensitive site (DHS) at the core promoter (Wang and Zhu, 2003, 2004) and several other DHSs downstream and upstream of the core promoter (Wang et al., 2009), suggesting the potential positions for regulatory chromatin elements. In telomerase-negative cells, HDAC inhibition by trichostatin $A$ resulted in an opening of this condensed chromatin domain, leading to an activated transcription from the $h T E R T$ gene (Wang and Zhu, 2004). These results indicated that the native chromatin environment was critical for the tight regulation of the hTERT gene.

The chromatin environments of the native loci may also contribute to the differential regulation of $h T E R T$ and $m T E R T$ genes. Both genes were down regulated during cellular differentiation (Wang et al., 2009), yet repression of the hTERT gene was much stronger than that of the mTERT gene. Since transiently transfected hTERT promoters were not repressed in differentiated cells, the stringent hTERT regulation in somatic cells likely depended on the native chromatin environment (Wang and Zhu, 2003; Wang et al., 2009). Interestingly, while the $h T E R T$ locus was located within a nuclease-resistant condensed chromatin domain in human cells, a corresponding chromatin domain was not detected for the $m T E R T$ locus (Wang et al., 2009). Taken together, these studies indicated that, unlike repression of the mTERT gene, the condensed native chromatin environment of the hTERT locus was central to its silencing during cell differentiation.

\section{REGULATION OF THE $h$ TERT GENE IN TUMORIGENESIS}

Whereas the $h T E R T$ gene is repressed in most somatic cells, telomerase activity is detected in the majority of cancer cells (Kim et al., 1994). Several mechanisms may contribute to the hTERT activation in cancer cells. First, transcriptional activators that are expressed in cancer cells may lead to activated transcription from the $h T E R T$ gene. For example, it was reported that the $h T E R T$ gene was activated by oncoprotein C-Myc, through binding to the E-boxes at the core promoter in normal and cancer cells (Wang et al., 1998; Greenberg et al., 1999). In addition, it was also shown that the hTERT promoter was activated by the viral oncoprotein E6 
from a subset of human papillomaviruses (HPVs), by binding to the E-boxes in epithelial cells (Klingelhutz et al., 1996; Veldman et al., 2003; Xu et al., 2008b). Second, activation of the $h T E R T$ gene may result from the loss or inactivation of transcriptional repressors in cancer cells. Transforming growth factor $\beta$ (TGF- $\beta$ ) family proteins, a group of cytokines that inhibit cell proliferation and promote differentiation in many cell types, have been proposed to initiate a tumor suppressor pathway. An important mechanism of the tumor suppression by TGF- $\beta$ may be through inhibition of the $h T E R T$ gene transcription ( $\mathrm{Li}$ and Liu, 2007). It was recently reported that TGF- $\beta$ and related protein BMP7 inhibited hTERT transcription in several cancer cell lines (Li et al., 2006; Cassar et al., 2008). Repression of the hTERT promoter required the TGF- $\beta$ signaling transducer protein Smad3, which translocated to nuclei upon activation of the pathway and bound to the hTERT promoter either directly or through its interaction with c-Myc (Li et al., 2006). Thus, disruption of the TGF- $\beta$ signaling would lead to an activation of the $h T E R T$ gene in cancer cells (Yaswen and Stampfer, 2002).

In addition to overexpression of transcriptional activators and loss of repressors, available evidences also indicated that activation of the $h T E R T$ gene in many cancer cells involved additional genetic and epigenetic mechanisms. For example, Bazarov et al. recently reported that c-Myc overexpression was insufficient to induce a significant increase of hTERT transcription (Bazarov et al., 2009). In c-Mycimmortalized human mammary epithelial cells, telomerase activation was accompanied by the amplification of either the whole or a portion of chromosome 5, where the hTERT locus is located. Several other reports have also shown that the hTERT gene was amplified in many cancer cell lines and primary tumors, including those of brain, breast, cervix, liver, and lung origins (Zhang et al., 2000; Zhang et al., 2002; Takuma et al., 2004), as well as primary and metastatic melanomas (Pirker et al., 2003). However, in the majority of cases, the amplification ratio, the ratio of $h T E R T$ gene copy number to the number of chromosome $5 p$, was less than two (Zhang et al., 2000; Pirker et al., 2003; Cao et al., 2008). Because transcription from the endogenous hTERT gene was very low in most human somatic tissues (Wright et al., 1996; Ducrest et al., 2001; Horikawa et al., 2005), the modest amplification could not have accounted for the large increases of hTERT mRNA expression in most cancer cells. Indeed, no statistically significant association was found between the copy number of the hTERT gene and its expression level or telomerase activity in the studies of a large set of colorectal carcinomas (Palmqvist et al., 2005), suggesting that amplifications of the $h T E R T$ locus per se was not a direct cause of hTERT activation and additional genetic or epigenetic events were likely involved.

In fact, the hTERT promoter was subjected to genetic alterations in cancer cells. It was shown that viruses frequently integrated into sequences in the proximity of the hTERT promoter in hepatitis B virus (HBV)-induced hepatocellular carcinoma and HPV-induced cervical cancers (Ferber et al., 2003). Most of these integrations occurred within the hTERT promoter or upstream region and one integration was found in intron 3 without altering the coding sequence, indicating that activation of telomerase by these viral integration promoted tumor progression.

Recently, we also detected that, the $h T E R T$ gene, located near the telomere of chromosom $5 p$, was translocated in telomerase-positive cell lines but not in their parental precrisis cells and telomerase-negative cell lines (Zhao et al., 2009). Detailed Southern analysis mapped the breakage points to the upstream region of the hTERT promoter, indicating that the $h T E R T$ gene was the direct target of these chromosomal rearrangements. Moreover, the levels of hTERT mRNA in immortal cell lines correlated inversely with the distance between chromosomal breakage points and the hTERT promoter. Since the $h T E R T$ locus was embedded in a condensed chromatin domain (Wang and Zhu, 2004), genomic rearrangements would have allowed the hTERT promoter to escape the repressive chromatin environment and thereby activate the telomerase gene, leading to cellular immortalization (Fig. 4).

In the oncogene-induced in vitro immortalization models of human fibroblasts, normal fibroblasts were first transformed with the SV40 T antigens, allowing the cells to overcome the M1 senesence and acquire an extended life span (Shay and Wright, 1989; Zhu et al., 1999). These cells continued to proliferate and eventually entered an M2 crisis when their telomeres became critically short and lost the capping function (Blackburn et al., 2000). During the crisis, dysfunctional telomeres formed end-to-end chromosome fusions, initiating breakage-fusion-bridge cycles and consequently a mitotic catastrophe (Counter et al., 1994; Zhu et al., 1999). Only very rarely did cells survive the crisis and became immortal lines (Shay and Wright, 1989; Wang and Zhu, 2003). The chromosomal breakages at the hTERT locus and subsequent ligations to heterologous regions by non-homologous end joining (NHEJ) led to nonreciprocal translocations, such as those present in telomerase-positive immortal cells. The very rare cells in which the hTERT gene was activated survived this crisis and were ultimately established as immortal cell lines. In fact, the hTERT gene was subjected to rearrangements in all telomerase-positive immortal fibroblast lines examined thus far, suggesting that translocation of the $h T E R T$ gene were caused by telomere-induced crisis (Shay and Wright, 1989; Wang and Zhu, 2003). This might explain the observation that in vitro cellular immortalization events are extremely rare and only occur following telomereinduced crisis (Shay and Wright, 1989; Zhu et al., 1999; Maser et al., 2002).

It has been reported that telomere-induced crisis occurred during tumorigenesis and was an important barrier for tumor 


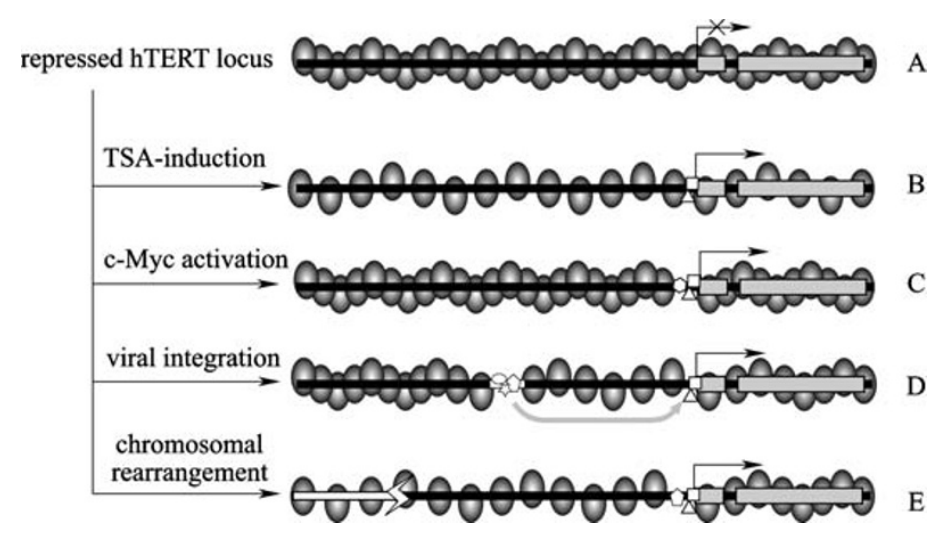

Figure 4. Models of hTERT activation in human cells. (A) The hTERT locus is embedded in a condensed chromatin domain in normal human fibroblasts and pre-crisis cells. As a result, the promoter is inaccessible to transcription activators. (B) Inhibition of HDACs by trichostatin A results in chromatin decondensation and the opening of the hTERT promoter. (C) Overexpression of activators, such the oncoprotein c-Myc, induces the hTERT transcription. (D) Integration of viral sequences in the proximity of the hTERT promoter leads to transcriptional activation of the $h T E R T$ gene. (E) Chromosomal translocations allow the hTERT promoter to escape the repressive chromatin environment. Ovals represent nucleosomes. Gray rectangles denote the first and second hTERT exons. Black bars are genomic sequences upstream of the hTERT promoter; white bars are heterologous upstream genomic sequence fused to the translocated $h T E R T$ allele. Horizontal arrows indicate the TSS and the direction of transcription. White polygons at the hTERT promoter symbolize various transcription activators.

progression (Maser et al., 2002; Greenberg, 2005; Hornsby, 2007). Therefore, activation of the $h T E R T$ gene by telomereinduced crisis might also take place during tumor development, consistent with the notion that the crisis was a mutational mechanism that generated diverse genetic alterations required for cancer progression (Greenberg, 2005; Hornsby, 2007); one of these alterations could be telomerase activation through rearrangements of the hTERT gene.

\section{CONCLUSIONS}

A large body of evidence accumulated from intensive investigations in the last decade has revealed that regulation of the $h T E R T$ gene is a very complex process. In addition to a number of transcription factors that bind and regulate the hTERT promoter, the repressive chromatin environment and nucleosomal conformation appear to be one of the major mechanisms that tightly suppress the $h T E R T$ gene in majority of human somatic cells (Fig. 4A). The repressed hTERT promoter can be activated by multiple mechanisms in different cell types. Inhibition of HDACs leads to global histone acetylation and decondensation of the $h T E R T$ locus (Fig. 4B). Sequence-specific transcription activators, such as C-Myc, may bind to the hTERT promoter and activate its transcription (Fig. 4C), although it was unclear whether c-Myc binding by itself was sufficient to induce hTERT transcription. The hTERT promoter may also be activated by integration of viral sequences at its proximity in some virus-induced cancers (Fig. 4D). In addition, hTERT gene amplifications in many cancers has been reported, although multiple copies of the repressed gene are unlikely to yield sufficient amount of the hTERT transcript. Gene amplifications combined with other genetic or epigenetic mechanisms may lead to a marked activation of hTERT transcription during tumorigenesis. In cancer cells, it may not be the increased copy number of the $h T E R T$ gene, but the escape of the hTERT promoter from its native repressive chromatin environment, as a result of chromosomal rearrangements, that leads to the significant increases in hTERT transcription (Fig. 4E). Chromosomal translocations of the $h T E R T$ locus may in fact be an important mechanism of telomerase activation, as it occurs through dysfunctional telomere-induced crisis during the progression of many cancers and telomerase activation is one of the few means that allows cells to escape this crisis.

\section{ACKNOWLEDGEMENTS}

The studies in the authors' laboratory were supported by NIH grant GM071725. Jiyue Zhu was a Research Scholar of American Cancer Society. Shuwen Wang was partly supported by a Dean's Feasibility Grant at Pennsylvania State College of Medicine.

\section{ABBREVIATIONS}

ChIP, chromatin immunoprecipitation; DHS, DNase I hypersensitive site; HBV, hepatitis B virus; HDAC, histone deacetylase; HPV, human papillomavirus; iPS cells, induced pluripotent stem cells; LSD1, lysine-specific demethylase 1; MAPK, mitogen-activated kinase; NHEJ, non-homologous end joining; TERT, telomerase reverse transcriptase; TGF- $\beta$, transforming growth factor $\beta$; TSS, transcription start site; WT-1, Wilm's tumor 1 


\section{REFERENCES}

Aisner, D.L., Wright, W.E., and Shay, J.W. (2002). Telomerase regulation: not just flipping the switch. Curr Opin Genet Dev 12, 80-85.

Akiyama, M., Hideshima, T., Hayashi, T., Tai, Y.T., Mitsiades, C.S., Mitsiades, N., Chauhan, D., Richardson, P., Munshi, N.C., and Anderson, K.C. (2003). Nuclear factor-kappaB p65 mediates tumor necrosis factor alpha-induced nuclear translocation of telomerase reverse transcriptase protein. Cancer Res 63, 18-21.

Atkinson, S.P., Hoare, S.F., Glasspool, R.M., and Keith, W.N. (2005). Lack of telomerase gene expression in alternative lengthening of telomere cells is associated with chromatin remodeling of the hTR and hTERT gene promoters. Cancer Res 65, 7585-7590.

Bazarov, A.V., Hines, W.C., Mukhopadhyay, R., Beliveau, A., Melodyev, S., Zaslavsky, Y., and Yaswen, P. (2009). Telomerase activation by c-Myc in human mammary epithelial cells requires additional genomic changes. Cell Cycle 8, 3373-3378.

Blackburn, E.H., Chan, S., Chang, J., Fulton, T.B., Krauskopf, A., McEachern, M., Prescott, J., Roy, J., Smith, C., and Wang, H. (2000). Molecular manifestations and molecular determinants of telomere capping. Cold Spring Harb Symp Quant Biol 65, 253-263.

Blasco, M.A., Funk, W., Villeponteau, B., and Greider, C.W. (1995). Functional characterization and developmental regulation of mouse telomerase RNA. Science 269, 1267-1270.

Blasco, M.A., Lee, H.W., Hande, M.P., Samper, E., Lansdorp, P.M., DePinho, R.A., and Greider, C.W. (1997). Telomere shortening and tumor formation by mouse cells lacking telomerase RNA [see comments]. Cell 91, 25-34.

Blasco, M.A., Rizen, M., Greider, C.W., and Hanahan, D. (1996). Differential regulation of telomerase activity and telomerase RNA during multi-stage tumorigenesis. Nature Genetics 12, 200-204.

Bodnar, A.G., Ouellette, M., Frolkis, M., Holt, S.E., Chiu, C.P., Morin, G.B., Harley, C.B., Shay, J.W., Lichtsteiner, S., and Wright, W.E. (1998). Extension of life-span by introduction of telomerase into normal human cells [see comments]. Science 279, 349-352.

Cao, Y., Bryan, T.M., and Reddel, R.R. (2008). Increased copy number of the TERT and TERC telomerase subunit genes in cancer cells. Cancer Sci 99, 1092-1099.

Cassar, L., Li, H., Pinto, A.R., Nicholls, C., Bayne, S., and Liu, J.P. (2008). Bone morphogenetic protein-7 inhibits telomerase activity, telomere maintenance, and cervical tumor growth. Cancer Res 68, 9157-9166.

Chatagnon, A., Bougel, S., Perriaud, L., Lachuer, J., Benhattar, J., and Dante, R. (2009). Specific association between the methylCpG-binding domain protein 2 and the hypermethylated region of the human telomerase reverse transcriptase promoter in cancer cells. Carcinogenesis 30, 28-34.

Chiu, C.P., Dragowska, W., Kim, N.W., Vaziri, H., Yui, J., Thomas, T. E., Harley, C.B., and Lansdorp, P.M. (1996). Differential expression of telomerase activity in hematopoietic progenitors from adult human bone marrow. Stem Cells 14, 239-248.

Cohen, S.B., Graham, M.E., Lovrecz, G.O., Bache, N., Robinson, P. J., and Reddel, R.R. (2007). Protein composition of catalytically active human telomerase from immortal cells. Science 315 , 1850-1853.

Collins, K. (2000). Mammalian telomeres and telomerase. Current Opinion in Cell Biology 12, 378-383.
Cong, Y.S., and Bacchetti, S. (2000). Histone deacetylation is involved in the transcriptional repression of hTERT in normal human cells. J Biol Chem 275, 35665-35668.

Cong, Y.S., Wen, J., and Bacchetti, S. (1999). The human telomerase catalytic subunit hTERT: organization of the gene and characterization of the promoter. Hum Mol Genet 8, 137-142.

Counter, C.M., Botelho, F.M., Wang, P., Harley, C.B., and Bacchetti, S. (1994). Stabilization of short telomeres and telomerase activity accompany immortalization of Epstein-Barr virus-transformed human B lymphocytes. J Virol 68, 3410-3414.

Counter, C.M., Hahn, W.C., Wei, W., Caddle, S.D., Beijersbergen, R. L., Lansdorp, P.M., Sedivy, J.M., and Weinberg, R.A. (1998). Dissociation among in vitro telomerase activity, telomere maintenance, and cellular immortalization. Proc Natl Acad Sci U S A 95, 14723-14728.

Crowe, D.L., Nguyen, D.C., Tsang, K.J., and Kyo, S. (2001). E2F-1 represses transcription of the human telomerase reverse transcriptase gene. Nucleic Acids Res 29, 2789-2794.

de la Serna, I.L., Ohkawa, Y., and Imbalzano, A.N. (2006). Chromatin remodelling in mammalian differentiation: lessons from ATPdependent remodellers. Nat Rev Genet 7, 461-473.

Dessain, S.K., Yu, H., Reddel, R.R., Beijersbergen, R.L., and Weinberg, R.A. (2000). Methylation of the human telomerase gene CpG island. Cancer Res 60, 537-541.

Devereux, T.R., Horikawa, I., Anna, C.H., Annab, L.A., Afshari, C.A., and Barrett, J.C. (1999). DNA methylation analysis of the promoter region of the human telomerase reverse transcriptase (hTERT) gene. Cancer Res 59, 6087-6090.

Ducrest, A.L., Amacker, M., Mathieu, Y.D., Cuthbert, A.P., Trott, D.A., Newbold, R.F., Nabholz, M., and Lingner, J. (2001). Regulation of human telomerase activity: repression by normal chromosome 3 abolishes nuclear telomerase reverse transcriptase transcripts but does not affect c-Myc activity. Cancer Res 61, 7594-7602.

Ducrest, A.L., Szutorisz, H., Lingner, J., and Nabholz, M. (2002). Regulation of the human telomerase reverse transcriptase gene. Oncogene 21, 541-552.

Dwyer, J., Li, H., Xu, D., and Liu, J.P. (2007). Transcriptional regulation of telomerase activity: roles of the the Ets transcription factor family. Ann N Y Acad Sci 1114, 36-47.

Ferber, M.J., Montoya, D.P., Yu, C., Aderca, I., McGee, A., Thorland, E.C., Nagorney, D.M., Gostout, B.S., Burgart, L.J., Boix, L., et al. (2003). Integrations of the hepatitis B virus (HBV) and human papillomavirus (HPV) into the human telomerase reverse transcriptase (hTERT) gene in liver and cervical cancers. Oncogene 22, 3813-3820.

Forsyth, N.R., Elder, F.F., Shay, J.W., and Wright, W.E. (2005). Lagomorphs (rabbits, pikas and hares) do not use telomeredirected replicative aging in vitro. Mech Ageing Dev126, 685-691.

Fujimoto, K., Kyo, S., Takakura, M., Kanaya, T., Kitagawa, Y., Itoh, H., Takahashi, M., and Inoue, M. (2000). Identification and characterization of negative regulatory elements of the human telomerase catalytic subunit (hTERT) gene promoter: possible role of MZF-2 in transcriptional repression of hTERT. Nucleic Acids Res 28, 2557-2562.

Günes, C., Lichtsteiner, S., Vasserot, A.P., and Englert, C. (2000). Expression of the hTERT gene is regulated at the level of transcriptional initiation and repressed by Mad1. Cancer Res 60, 2116-2121. 
Ge, Z., Li, W., Wang, N., Liu, C., Zhu, Q., Bjorkholm, M., Gruber, A., and $\mathrm{Xu}$, D. (2009). Chromatin remodeling: recruitment of histone demethylase RBP2 by Mad1 for transcriptional repression of a Myc target gene, telomerase reverse transcriptase. Faseb J. In press.

Ge, Z., Liu, C., Bjorkholm, M., Gruber, A., and Xu, D. (2006). Mitogenactivated protein kinase cascade-mediated histone $\mathrm{H} 3$ phosphorylation is critical for telomerase reverse transcriptase expression/ telomerase activation induced by proliferation. Mol Cell Biol 26, 230-237.

Goueli, B.S., and Janknecht, R. (2004). Upregulation of the Catalytic Telomerase Subunit by the Transcription Factor ER81 and Oncogenic HER2/Neu, Ras, or Raf. Mol Cell Biol 24, 25-35.

Greenberg, R.A. (2005). Telomeres, crisis and cancer. Curr Mol Med 5, 213-218.

Greenberg, R.A., Allsopp, R.C., Chin, L., Morin, G.B., and DePinho, R.A. (1998). Expression of mouse telomerase reverse transcriptase during development, differentiation and proliferation. Oncogene 16, 1723-1730.

Greenberg, R.A., O'Hagan, R.C., Deng, H., Xiao, Q., Hann, S.R., Adams, R.R., Lichtsteiner, S., Chin, L., Morin, G.B., and DePinho, R.A. (1999). Telomerase reverse transcriptase gene is a direct target of c-Myc but is not functionally equivalent in cellular transformation. Oncogene 18, 1219-1226.

Guilleret, I., and Benhattar, J. (2003). Demethylation of the human telomerase catalytic subunit (hTERT) gene promoter reduced hTERT expression and telomerase activity and shortened telomeres. Exp Cell Res 289, 326-334.

Guilleret, I., Yan, P., Grange, F., Braunschweig, R., Bosman, F.T., and Benhattar, J. (2002). Int J Cancer 101, 335-341.

Hahn, W.C., Counter, C.M., Lundberg, A.S., Beijersbergen, R.L., Brooks, M.W., and Weinberg, R.A. (1999a). Creation of human tumour cells with defined genetic elements [see comments]. Nature 400, 464- 468.

Hahn, W.C., Stewart, S.A., Brooks, M.W., York, S.G., Eaton, E., Kurachi, A., Beijersbergen, R.L., Knoll, J.H., Meyerson, M., and Weinberg, R.A. (1999b). Inhibition of telomerase limits the growth of human cancer cells. Nat Med 5, 1164-1170.

Harrington, L., McPhail, T., Mar, V., Zhou, W., Oulton, R., Bass, M.B., Arruda, I., and Robinson, M.O. (1997). A mammalian telomeraseassociated protein [see comments]. Science 275, 973-977.

Horikawa, I., Cable, P.L., Afshari, C., and Barrett, J.C. (1999). Cloning and characterization of the promoter region of human telomerase reverse transcriptase gene. Cancer Res 59, 826-830.

Horikawa, I., Cable, P.L., Mazur, S.J., Appella, E., Afshari, C.A., and Barrett, J.C. (2002). Downstream E-Box-mediated Regulation of the Human Telomerase Reverse Transcriptase (hTERT) Gene Transcription: Evidence for an Endogenous Mechanism of Transcriptional Repression. Mol Biol Cell 13, 2585-2597.

Horikawa, I., Chiang, Y.J., Patterson, T., Feigenbaum, L., Leem, S.H., Michishita, E., Larionov, V., Hodes, R.J., and Barrett, J.C. (2005). Differential cis-regulation of human versus mouse TERT gene expression in vivo: identification of a human-specific repressive element. Proc Natl Acad Sci U S A 102, 18437-18442.

Horikawa, I., Oshimura, M., and Barrett, J.C. (1998). Repression of the telomerase catalytic subunit by a gene on human chromosome 3 that induces cellular senescence. Mol Carcinog 22, 65-72.

Hornsby, P.J. (2007). Senescence as an anticancer mechanism. J Clin Oncol 25, 1852-1857.
Hou, M., Wang, X., Popov, N., Zhang, A., Zhao, X., Zhou, R., Zetterberg, A., Bjorkholm, M., Henriksson, M., Gruber, A., et al. (2002). The histone deacetylase inhibitor trichostatin A derepresses the telomerase reverse transcriptase (hTERT) gene in human cells. Exp Cell Res 274, 25-34.

Janknecht, R. (2004). On the road to immortality: hTERT upregulation in cancer cells. FEBS Lett 564, 9-13.

Jenuwein, T., and Allis, C.D. (2001). Translating the histone code.[see comment]. Science 293, 1074-1080.

Kaeser, M.D., and Emerson, B.M. (2006). Remodeling plans for cellular specialization: unique styles for every room. Curr Opin Genet Dev 16, 508-512.

Kang, S.S., Kwon, T., Kwon, D.Y., and Do, S.I. (1999). Akt protein kinase enhances human telomerase activity through phosphorylation of telomerase reverse transcriptase subunit. J Biol Chem 274, 13085-13090.

Kim, N.W., Piatyszek, M.A., Prowse, K.R., Harley, C.B., West, M.D., Ho, P.L., Coviello, G.M., Wright, W.E., Weinrich, S.L., and Shay, J. W. (1994). Specific association of human telomerase activity with immortal cells and cancer [see comments]. Science 266, 2011-2015.

Klingelhutz, A.J., Foster, S.A., and McDougall, J.K. (1996). Telomerase activation by the $\mathrm{E} 6$ gene product of human papillomavirus type 16 . Nature $380,79-82$.

Kyo, S., Takakura, M., Fujiwara, T., and Inoue, M. (2008). Understanding and exploiting hTERT promoter regulation for diagnosis and treatment of human cancers. Cancer Sci 99, 1528-1538.

Kyo, S., Takakura, M., Kanaya, T., Zhuo, W., Fujimoto, K., Nishio, Y., Orimo, A., and Inoue, M. (1999). Estrogen activates telomerase. Cancer Res 59, 5917-5921.

Kyo, S., Takakura, M., Taira, T., Kanaya, T., Itoh, H., Yutsudo, M., Ariga, H., and Inoue, M. (2000). Sp1 cooperates with c-Myc to activate transcription of the human telomerase reverse transcriptase gene (hTERT). Nucleic Acids Res 28, 669-677.

$\mathrm{Li}, \mathrm{H}$., and Liu, J.P. (2007). Mechanisms of action of TGF-beta in cancer: evidence for Smad3 as a repressor of the hTERT gene. Ann N Y Acad Sci 1114, 56-68.

Li, H., Xu, D., Li, J., Berndt, M.C., and Liu, J.P. (2006). Transforming growth factor beta suppresses human telomerase reverse transcriptase (hTERT) by Smad3 interactions with c-Myc and the hTERT gene. J Biol Chem 281, 25588-25600.

Lin, S.Y., and Elledge, S.J. (2003). Multiple tumor suppressor pathways negatively regulate telomerase. Cell 113, 881-889.

Lingner, J., Hughes, T.R., Shevchenko, A., Mann, M., Lundblad, V., and Cech, T.R. (1997). Reverse transcriptase motifs in the catalytic subunit of telomerase [see comments]. Science 276, 561-567.

Liu, C., Fang, X., Ge, Z., Jalink, M., Kyo, S., Bjorkholm, M., Gruber, A., Sjoberg, J., and Xu, D. (2007). The telomerase reverse transcriptase (hTERT) gene is a direct target of the histone methyltransferase SMYD3. Cancer Res 67, 2626-2631.

Liu, L., Lai, S., Andrews, L.G., and Tollefsbol, T.O. (2004). Genetic and epigenetic modulation of telomerase activity in development and disease. Gene 340, 1-10.

Martin-Rivera, L., Herrera, E., Albar, J.P., and Blasco, M.A. (1998). Expression of mouse telomerase catalytic subunit in embryos and adult tissues. Proc Natl Acad Sci U S A 95, 10471-10476.

Maser, R.S., DePinho, R.A., and Masera, G. (2002). Connecting chromosomes, crisis, and cancer. Science 297, 565-569. 
Masutomi, K., Yu, E.Y., Khurts, S., Ben-Porath, I., Currier, J.L., Metz, G.B., Brooks, M.W., Kaneko, S., Murakami, S., DeCaprio, J.A., et al. (2003). Telomerase maintains telomere structure in normal human cells. Cell 114, 241-253.

Meyerson, M., Counter, C.M., Eaton, E.N., Ellisen, L.W., Steiner, P., Caddle, S.D., Ziaugra, L., Beijersbergen, R.L., Davidoff, M.J., Liu, Q., et al. (1997). hEST2, the putative human telomerase catalytic subunit gene, is up-regulated in tumor cells and during immortalization. Cell 90, 785-795.

Morin, G.B. (1989). The human telomere terminal transferase enzyme is a ribonucleoprotein that synthesizes TTAGGG repeats. Cell 59, 521-529.

Nakamura, T.M., Morin, G.B., Chapman, K.B., Weinrich, S.L., Andrews, W.H., Lingner, J., Harley, C.B., and Cech, T.R. (1997). Telomerase catalytic subunit homologs from fission yeast and human [see comments]. Science 277, 955-959.

Nash, S.R., Giros, B., Kingsmore, S.F., Kim, K.M., el-Mestikawy, S., Dong, Q., Fumagalli, F., Seldin, M.F., and Caron, M.G. (1998). Cloning, gene structure and genomic localization of an orphan transporter from mouse kidney with six alternatively-spliced isoforms. Receptors Channels 6, 113-128.

Oh, S., Song, Y., Yim, J., and Kim, T.K. (1999). The Wilms' tumor 1 tumor suppressor gene represses transcription of the human telomerase reverse transcriptase gene. J Biol Chem 274, 37473-37478.

Palmqvist, R., Zhang, A., Xu, D., Golovleva, I., Norrback, K.F., Gruber, A., Oberg, A., Stenling, R., and Roos, G. (2005). hTERT gene copy number is not associated with hTERT RNA expression or telomerase activity in colorectal cancer. Int J Cancer 116, 395-400.

Pirker, C., Holzmann, K., Spiegl-Kreinecker, S., Elbling, L., Thallinger, C., Pehamberger, H., Micksche, M., and Berger, W. (2003). Chromosomal imbalances in primary and metastatic melanomas: over-representation of essential telomerase genes. Melanoma Res 13, 483-492.

Prowse, K.R., and Greider, C.W. (1995). Developmental and tissuespecific regulation of mouse telomerase and telomere length. Proc Natl Acad Sci U S A 92, 4818-4822.

Renaud, S., Bosman, F.T., and Benhattar, J. (2003). Implication of the exon region in the regulation of the human telomerase reverse transcriptase gene promoter. Biochem Biophys Res Commun 300, 47-54.

Renaud, S., Loukinov, D., Bosman, F.T., Lobanenkov, V., and Benhattar, J. (2005). CTCF binds the proximal exonic region of hTERT and inhibits its transcription. Nucleic Acids Res 33, 6850-6860.

Ritz, J.M., Kuhle, O., Riethdorf, S., Sipos, B., Deppert, W., Englert, C., and Gunes, C. (2005). A novel transgenic mouse model reveals humanlike regulation of an 8-kbp human TERT gene promoter fragment in normal and tumor tissues. Cancer Res 65, 1187-1196.

Rudolph, K.L., Chang, S., Lee, H.W., Blasco, M., Gottlieb, G.J., Greider, C., and DePinho, R.A. (1999). Longevity, stress response, and cancer in aging telomerase-deficient mice. Cell 96, 701-712.

Shay, J.W., and Bacchetti, S. (1997). A survey of telomerase activity in human cancer. Eur J Cancer 33, 787-791.

Shay, J.W., and Wright, W.E. (1989). Quantitation of the frequency of immortalization of normal human diploid fibroblasts by SV40 large T-antigen. Exp Cell Res 184, 109-118.

Shippen-Lentz, D., and Blackburn, E.H. (1990). Functional evidence for an RNA template in telomerase. Science 247, 546-552.

Takahashi, K., Tanabe, K., Ohnuki, M., Narita, M., Ichisaka, T., Tomoda, K., and Yamanaka, S. (2007). Induction of pluripotent stem cells from adult human fibroblasts by defined factors.[see comment]. Cell 131, 861-872.

Takahashi, K., and Yamanaka, S. (2006). Induction of pluripotent stem cells from mouse embryonic and adult fibroblast cultures by defined factors.[see comment]. Cell 126, 663-676.

Takakura, M., Kyo, S., Inoue, M., Wright, W.E., and Shay, J.W. (2005). Function of AP-1 in transcription of the telomerase reverse transcriptase gene (TERT) in human and mouse cells. Mol Cell Biol 25, 8037-8043.

Takakura, M., Kyo, S., Kanaya, T., Hirano, H., Takeda, J., Yutsudo, M., and Inoue, M. (1999). Cloning of human telomerase catalytic subunit (hTERT) gene promoter and identification of proximal core promoter sequences essential for transcriptional activation in immortalized and cancer cells. Cancer Res 59, 551-557.

Takakura, M., Kyo, S., Sowa, Y., Wang, Z., Yatabe, N., Maida, Y., Tanaka, M., and Inoue, M. (2001). Telomerase activation by histone deacetylase inhibitor in normal cells. Nucleic Acids Res 29 3006-3011.

Takuma, Y., Nouso, K., Kobayashi, Y., Nakamura, S., Tanaka, H., Matsumoto, E., Fujikawa, T., Suzuki, M., Hanafusa, T., and Shiratori, Y. (2004). Telomerase reverse transcriptase gene amplification in hepatocellular carcinoma. J Gastroenterol Hepatol 19, 1300-1304.

Veldman, T., Liu, X., Yuan, H., and Schlegel, R. (2003). Human papillomavirus $\mathrm{E} 6$ and Myc proteins associate in vivo and bind to and cooperatively activate the telomerase reverse transcriptase promoter. Proc Natl Acad Sci U S A 100, 8211-8216.

Venteicher, A.S., Abreu, E.B., Meng, Z., McCann, K.E., Terns, R.M., Veenstra, T.D., Terns, M.P., and Artandi, S.E. (2009). A human telomerase holoenzyme protein required for Cajal body localization and telomere synthesis. Science 323, 644-648.

Wang, J., Xie, L.Y., Allan, S., Beach, D., and Hannon, G.J. (1998). Myc activates telomerase. Genes Dev 12, 1769-1774.

Wang, S., Hu, C., and Zhu, J. (2007). Transcriptional silencing of a novel hTERT reporter locus during in vitro differentiation of mouse embryonic stem cells. Mol Biol Cell 18, 669-677.

Wang, S., Robertson, G.P., and Zhu, J. (2004). A novel human homologue of Drosophila polycomblike gene is up-regulated in multiple cancers. Gene 343, 69-78.

Wang, S., Zhao, Y., Hu, C., and Zhu, J. (2009). Differential repression of human and mouse TERT genes during cell differentiation. Nucleic Acids Res 37, 2618-2629.

Wang, S., and Zhu, J. (2003). Evidence for a relief of repression mechanism for activation of the human telomerase reverse transcriptase promoter. J Biol Chem 278, 18842-18850.

Wang, S., and Zhu, J. (2004). The hTERT gene is embedded in a nuclease-resistant chromatin domain. J Biol Chem 279, 55401-55410.

Weng, N.P., Levine, B.L., June, C.H., and Hodes, R.J. (1996). Regulated expression of telomerase activity in human $\mathrm{T}$ lymphocyte development and activation. J Exp Med 183, 2471-2479.

Wernig, M., Meissner, A., Cassady, J.P., and Jaenisch, R. (2008). c$\mathrm{Myc}$ is dispensable for direct reprogramming of mouse fibroblasts. Cell Stem Cell 2, 10-12.

Wick, M., Zubov, D., and Hagen, G. (1999). Genomic organization 
and promoter characterization of the gene encoding the human telomerase reverse transcriptase (hTERT). Gene 232, 97-106.

Won, J., Yim, J., and Kim, T.K. (2002). Sp1 and Sp3 Recruit Histone Deacetylase to Repress Transcription of Human Telomerase Reverse Transcriptase (hTERT) Promoter in Normal Human Somatic Cells. J Biol Chem 277, 38230-38238.

Wright, W.E., Piatyszek, M.A., Rainey, W.E., Byrd, W., and Shay, J.W. (1996). Telomerase activity in human germline and embryonic tissues and cells. Dev Genet 18, 173-179.

Wu, K.J., Grandori, C., Amacker, M., Simon-Vermot, N., Polack, A., Lingner, J., and Dalla-Favera, R. (1999). Direct activation of TERT transcription by c-MYC. Nat Genet 21, 220-224.

Xu, D., Dwyer, J., Li, H., Duan, W., and Liu, J.P. (2008a). Ets2 maintains hTERT gene expression and breast cancer cell proliferation by interacting with c-Myc. J Biol Chem 283, 23567-23580.

Xu, D., Popov, N., Hou, M., Wang, Q., Bjorkholm, M., Gruber, A., Menkel, A.R., and Henriksson, M. (2001). Switch from Myc/Max to Mad1/Max binding and decrease in histone acetylation at the telomerase reverse transcriptase promoter during differentiation of HL60 cells. Proc Natl Acad Sci U S A 98, 3826-3831.

Xu, M., Luo, W., Elzi, D.J., Grandori, C., and Galloway, D.A. (2008b). NFX1 interacts with $\mathrm{mSin} 3 \mathrm{~A} /$ histone deacetylase to repress hTERT transcription in keratinocytes. Mol Cell Biol 28, 4819-4828.

Yasumoto, S., Kunimura, C., Kikuchi, K., Tahara, H., Ohji, H., Yamamoto, H., Ide, T., and Utakoji, T. (1996). Telomerase activity in normal human epithelial cells. Oncogene 13, 433-439.

Yaswen, P., and Stampfer, M.R. (2002). Molecular changes accompanying senescence and immortalization of cultured human mammary epithelial cells. Int J Biochem Cell Biol 34, 1382-1394.

Yi, X., Shay, J.W., and Wright, W.E. (2001). Quantitation of telomerase components and hTERT mRNA splicing patterns in immortal human cells. Nucleic Acids Res 29, 4818 4825.
Yu, J., Vodyanik, M.A., Smuga-Otto, K., Antosiewicz-Bourget, J., Frane, J.L., Tian, S., Nie, J., Jonsdottir, G.A., Ruotti, V., Stewart, R., et al. (2007). Induced pluripotent stem cell lines derived from human somatic cells. Science 318, 1917-1920.

Zhang, A., Zheng, C., Hou, M., Lindvall, C., Wallin, K.L., Angstrom, T., Yang, X., Hellstrom, A.C., Blennow, E., Bjorkholm, M., et al. (2002). Amplification of the telomerase reverse transcriptase (hTERT) gene in cervical carcinomas. Genes Chromosomes Cancer 34, 269-275.

Zhang, A., Zheng, C., Lindvall, C., Hou, M., Ekedahl, J., Lewensohn, R., Yan, Z., Yang, X., Henriksson, M., Blennow, E., et al. (2000). Frequent amplification of the telomerase reverse transcriptase gene in human tumors. Cancer Res 60, 6230-6235.

Zhang, Z., and Reese, J.C. (2004). Redundant mechanisms are used by Ssn6-Tup1 in repressing chromosomal gene transcription in Saccharomyces cerevisiae. J Biol Chem 279, 39240-39250.

Zhao, Y., Wang, S., Popova, E., Grigoryev, S., and Zhu, J. (2009). Rearrangement of Upstream Sequences of the hTERT Gene during Cellular Immortalization. Genes Chromosomes Cancer. In press.

Zhu, J., Wang, H., Bishop, J.M., and Blackburn, E.H. (1999). Telomerase extends the lifespan of virus-transformed human cells without net telomere lengthening [see comments]. Proc Natl Acad Sci U S A 96, 3723-3728.

Zhu, Q., Liu, C., Ge, Z., Fang, X., Zhang, X., Straat, K., Bjorkholm, M., and $\mathrm{Xu}, \mathrm{D}$. (2008). Lysine-specific demethylase 1 (LSD1) Is required for the transcriptional repression of the telomerase reverse transcriptase (hTERT) gene. PLoS One 3, e1446.

Zinn, R.L., Pruitt, K., Eguchi, S., Baylin, S.B., and Herman, J.G. (2007). hTERT is expressed in cancer cell lines despite promoter DNA methylation by preservation of unmethylated DNA and active chromatin around the transcription start site. Cancer Res 67, 194-201. 